\title{
Prediction of Resistance and Planing Attitude for Prismatic Planing Hull using OpenFOAM
}

\author{
XiangYu Shi®*, Yang Zhang®*; and Deuk-joon Yum®* \\ "Department of Naval Architecture and Ocean Engineering, Kunsan National University, Gunsan, Korea \\ *Ulsan Ship and Ocean College, LuDong University, Yantai, China

\section{OpenFOAM을 이용한 주형체 활주선의 저항 및 항주자세 추정} \\ 쉬샹위®* 장양 ${ }^{* *, * *}$ - 염덕준(1) \\ *국립군산대학교 조선해양공학과 \\ "로동대학교 울산조선해양대학
}

KEY WORDS: Planing hull 활주선, Fridsma hull 프리즈마 선형, RANS equation RANS 방정식, OpenFOAM 오픈폼, Overset mesh method 중첩격자 방법, Uncertainty analysis 불확실성 해석

\begin{abstract}
The prediction of the hydrodynamic performance of a planing hull vessel is an important and challenging topic for computational fluid dynamic (CFD) applications to naval hydrodynamics. In this paper, the resistance and planing attitude analysis for a Fridsma hull, which is a prismatic planing hull, in still water are numerically studied using OpenFOAM. OpenFOAM is an open source code package based on C++ libraries and the finite volume method (FVM) for the discretization of the RANS equation. The volume of fluid method (VOF) is used to capture the water-air interface and the SST $k-\omega$ model is used for the turbulence simulation. The overset mesh method is used to capture the large motion of the hull at higher speeds. Before the extensive analysis, uncertainty analyses using various time steps and grid sizes were performed for one ship speed case of $F n=1.19$.

The results of the present study are compared with those of a model test, other CFD research, and Savitsky's empirical formula. The results of the present study, following the trend of other CFD results, slightly over predict the resistance and under predict the sinkage and, more significantly, the trim.
\end{abstract}

\section{1. 서 론}

고성능 컴퓨터의 지속적인 성능 향상과 더불어 선박의 유체 역학 성능을 추정하는데 있어서 $\mathrm{CFD}($ Computational fluid dynamics)에 기반한 다양한 프로그램을 이용하는 것이 필수적인 사항이 되었다. 근래에는 소스 코드가 공개된 OpenFOAM을 이 용하는 연구가 새로운 선택으로 제공되고 있다. OpenFOAM프 로그램은 ANSYS: Fluent, Star-CCM+ 등 대규모 상업용 프로그 램과 마찬가지로 유한체적법(Finite volume method, FVM)에 기 반한 편미분방정식 수치해석 프로그램이지만 사용자가 특정한 해석기를 추가로 정의할 수 있도록 하여 선박의 유체역학 성능 추정에의 적용이 확대되고 있는 추세이다.

선박의 유체역학적 성능 추정에 전산유체역학을 적용한 근래 의 연구로, Mousavirrad et al.(2015)은 CFDSHIP-IOWA 프로그램
을 통하여 Fridsma 선형에 대한 저항성능과 운동성능을 추정하 였다. Islam and Soares(2017)는 Ropax 선형에 대한 파랑 중 저항 성능을 추정하였고 Go et al.(2016)은 수중 예인체에 대하여 6 자유도 운동을 추정하였다. 그리고 Bustos and Alvarado(2017)은 쌍동선에 대하여 저항성능 추정 연구를 하였지만 항주자세에 대한 연구는 수행하지 않았다. 소형 고속선의 운동성능과 관련 하여 Hassan et al.(2015)은 단이 있는 활주선(Stepped planing hull) 에 대하여 이론 및 $\mathrm{CFD}$ 해석을 통하여 트림 및 저항성능을 추 정하였다. Cucinotta and Sfravara(2018)는 CFD 해석과 모형시험 을 통하여 고속선박에 대한 저항성능을 연구하였으며 격자계의 동적 변형에 대하여는 중첩격자방법(Overset mesh method)을 사 용하였다.

최근에는 선박의 유체역학적 성능 해석에 고가의 대규모 상 업용 CFD 프로그램을 사용하는 것 보다는 소스가 공개되어 있

Received 26 July 2019, revised 4 August 2019, accepted 12 August 2019

Corresponding author Deuk-joon Yum: +82-63-469-1852, djyum@kunsan.ac.kr ORCID: https://orcid.org/0000-0003-2250-6937

(c) 2019, The Korean Society of Ocean Engineers

This is an open access article distributed under the terms of the creative commons attribution non-commercial license (http://creativecommons.org/licenses/by-nc/3.0) which permits unrestricted non-commercial use, distribution, and reproduction in any medium, provided the original work is properly cited. 
어 경제적이며 사용자가 목적에 맞게 특정한 해석기들을 추가 로 정의할 수 있는 OpenFOAM을 이용하는 연구가 활발하게 진 행되고 있다.

본 연구에서는 오픈소스 CFD 프로그램인 OpenFOAM(OpenCFD Ltd., 2017)을 이용하여 주형체 활주선인 Fridsma 선형(Fridsma, 1969)에 대하여 정수 중에 저항성능과 트림 및 부상량 등 항주자세 를 추정하였다. 특히, 활주선이 고속으로 활주할 때 발생하는 항주 자세의 큰 변화와 연관된 유체역학적 현상의 정도 높은 추정을 위하여 동적중첩격자 해석기인 'overInterDyMFoam'을 사용하였 다. 또한, 본격적인 $\mathrm{CFD}$ 해석에 앞서 활주상태의 선속인 $F n=1.19$ 에 대하여 격자 크기와 계산 시간 간격 변화에 따른 불확실성 해석 을 수행하였다.

마지막으로 OpenFOAM을 이용한 본 연구결과를 Fridsma의 실 험 결과, 타 CFD 해석 결과 및 Savitsky 경험식(Savitsky, 1964)과 의 비교를 통하여 분석하고 적용 가능성을 검증하였다.

\section{2. 수치해석 방법}

\subsection{OpenFOAM의 구성}

OpenFOAM은 유한체적법을 기반으로 하는 오픈소스 편미분 방정식 수치해석 프로그램이다. OpenFOAM의 구성은 화학, 난 류유동, 열에너지 및 구조역학 등 광범위한 공학분야에 적용되 는 다양한 해석기(Solver)들과 전후처리 툴(Pre-processing \& Post-processing tool)을 포함하고 있으며 해석목적에 따라서 다 수의 해석기들을 결합함에 의하여 원하는 수치해석 프로그램을 구성할 수 있다.

통상적으로 $\mathrm{CFD}$ 프로그램은 전처리, $\mathrm{CFD}$ 해석 및 후처리의 3 가지 절차가 순차적으로 진행되나 OpenFOAM은 User's interface 가 없으므로 모든 단계에서 Fig. 1 에 보는 바와 같이 경계조건이 정의된 ' 0 ' 파일, 격자와 난류모델 등이 정의된 'constant' 파일 및 시간제어, 이산화처리방법 등이 정의된 'system' 파일로 구성된 다. 그리고 OpenFOAM에서 제공되는 격자변환 툴을 이용하여 Fluent, Star-CCM+ 및 GAMBIT 등에서 생성된 격자계를 읽어 들 일 수 있다.

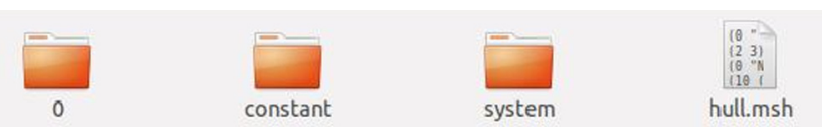

Fig. 1 Document composition of OpenFOAM

\subsection{CFD 해석기}

OpenFOAM을 이용한 유동해석에서의 지배방정식은 아래의 연속방정식과 RANS(Reynolds averaged navier stokes)방정식으로 구성된다.

$$
\begin{aligned}
& \nabla \cdot U=0 \\
& \frac{\partial U}{\partial t}+\nabla \cdot(U U)-\nabla \cdot(\nu \quad \nabla U)=-\nabla \frac{p}{\rho}+S
\end{aligned}
$$

여기서 $U$ 는 속도이며 $\rho$ 와 $S$ 는 각각 밀도 및 소스항으로 정의 된다.
자유수면 변형 해석에는 식 (3)의 $\operatorname{VOF}($ Volume of fraction)법 을 사용하였다.

$$
\frac{\partial \alpha}{\partial t}+\nabla \cdot(\alpha U)=0
$$

여기서 $\alpha($ air $: \alpha=0$, water $: \alpha=1)$ 는 $\mathrm{VOF}$ 이다.

유동장의 압력과 속도 연성해석에는 PISO(Pressure-implicit with splitting of operators)방법이 사용된다. 식 (2)에 대한 이산화 과 정을 통하여 다음의 식이 유도된다.

$$
A_{p} U=H(U)-\nabla p_{d}+S
$$

여기서 $A_{p}$ 는 대수방정식 매트릭스의 대각(Diagonal) 요소이고 $H(U), p_{d}$ 및 $S$ 는 각각 비대각(Off-diagonal) 요소, 동압력 및 소 스항이다. 대수방정식 해석기를 통하여 산출한 속도 예측값 $U^{*}$ 를 다시 식 (4)에 대입하고 식 (5)와 식 (6)의 과정을 거쳐 압력 포아송 방정식인 식 (7)을 얻는다.

$$
\begin{aligned}
& U^{*}=\frac{H\left(U^{*}\right)}{A_{p}}-\frac{\nabla p_{d}}{A_{p}}+\frac{S}{A_{p}} \\
& \nabla \cdot U^{*}=\nabla \cdot \widetilde{U}-\nabla \cdot\left(\frac{1}{A_{p}} \nabla p_{d}\right) \\
& \tilde{U}=\frac{H\left(U^{*}\right)}{A_{p}}+\frac{S}{A_{p}} \\
& \nabla \cdot\left(\frac{1}{A_{p}} \nabla p_{d}\right)=\nabla \cdot \tilde{U}
\end{aligned}
$$

식 (7)에서 산출된 새로운 $p_{d}^{*}$ 를 식 (4)에 대입하여 수정된 속 도 $U^{* *}$ 를 얻을 수 있다. 같은 방법으로 수정된 $H\left(U^{* *}\right), p_{d}^{* *}$ 및 $\widetilde{U^{*}}$ 를 수렴할 때까지 반복하여 계산한다.

\section{3 동적격자계(Dynamic mesh)}

OpenFOAM에서 사용되는 동적격자방법은 크게 격자변형방법 (Mesh deformation method)과 중첩격자방법 등 2가지 방법이 있다. 격자변형방법은 Fig. 2처럼 격자의 변형 과정 중에 전체 격자 수가 유지되며, 압력-속도 결합법을 통하여 격자의 노드(Node) 를 이동시키는 방법이다. 하지만 고속 활주선의 경우처럼 선속

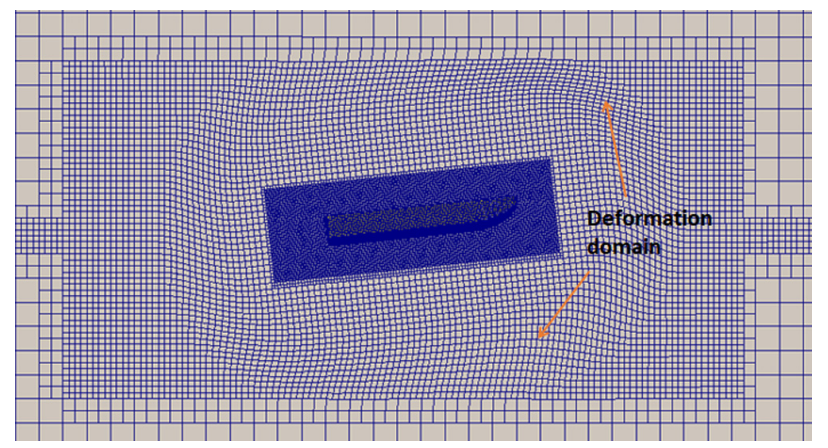

Fig. 2 Mesh deformation method 


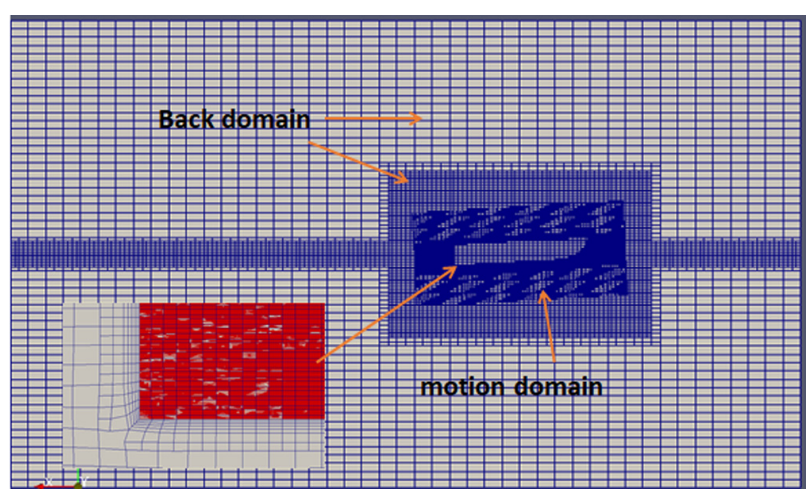

Fig. 3 Overset mesh method

에 따라서 흘수의 변화가 큰 선박은 정수 중 저항 및 항주자세 수치해석 시 노드의 이동거리가 커짐에 따라 수치해석 오차가 커지게 되며, 심지어 부피가 음수가 되는 격자가 발생하여 수치 해석 결과가 발산하게 된다.

중첩격자방법은 Fig. 3처럼 배경격자 영역과 운동격자 영역이 따로 있어서 수치해석 시에 중첩되는 경계영역만 고려하면 되고 격자의 변형이 발생하지 않으므로 격자변형으로 인하여 야기되 는 오차의 발생을 줄일 수 있다. 그리고 중첩격자는 배경격자 영 역과 운동격자 영역에 별도의 격자계를 구성한 후에 운동영역 격자계를 배경영역 격자계에 삽입하고 $\mathrm{DCI}($ Domain connectivity information)방법을 통하여 각각의 격자계에 포함된 유동장 정보 가 내삽법에 의하여 전달이 되도록 한다. 유동장 정보가 전달되 는 과정은 다음과 같다.

삽입되는 운동영역 격자계에서 'cellType' 표식을 통하여 아래 와 같이 0 에서 2 까지 격자의 유형을 지정한다.

$$
\begin{aligned}
& 0 \text { - calculated cell } \\
& 1 \text { - interpolated cell } \\
& 2 \text { - hole/inactive cell }
\end{aligned}
$$

유형 '2'로 지정된 격자에 대하여는 Cutting hole 처리를 하여 제거하며 남은 격자, 즉 유형 ' 1 '로 지정된 격자에 대하여는 내 삽법을 통하여 유동장 정보를 유형 ' 0 ' 격자와 상호 교환한다.

유동장 정보의 내삽을 위하여 OpenFOAM에서 사용하는 방법 에는 InverseDistance, TrackingInverseDistance, CellVolumeWeight 및 LeastSquares 등 4가지 방법이 있으며 본 연구에서는 Inverse Distance 방법을 사용하였다.

\section{4 난류 모델}

OpenFOAM에는 다양한 난류 모델을 제공되며, 본 연구에서는 $S S T k-\omega$ 모델을 사용하였다. SST k- $\omega$ 난류 모델은 Wilcox $k-\omega$ 모델과 $k-\epsilon$ 모델을 결합한 하이브리드 모델로 수송방정식의 형태는 식 (8)과 같다.

$$
\begin{gathered}
\frac{\partial k}{\partial t}+\nabla \cdot(U k)=\tilde{G}-\beta^{*} k \omega+\nabla \cdot\left[\left(\nu+\alpha_{k} \nu_{t}\right) \nabla k\right] \\
\frac{\partial \omega}{\partial t}+\nabla \cdot(U \omega)= \\
\gamma S^{2}-\beta \omega^{2}+\nabla \cdot\left[\left(\nu+\alpha_{\omega} \nu_{t}\right) \nabla \omega\right] \\
+\left(1-F_{1}\right) C D_{k \omega}
\end{gathered}
$$

여기서 $k$ 는 난류 에너지, $\omega$ 는 난류 에너지 소산 비율, $\tilde{G}$ 는 혼합 합수, $S$ 는 변형율의 불변도(Invariant measure of the strain rate)이 다. $F_{1}$ 은 다음의 식 (9)와 식 (10)으로 정의되는 혼합 함수로 벽 근처 영역에서는 $k-\omega$ 모델 $\left(F_{1}=1\right)$ 을, 자유 유동 영역에서는 $k-\epsilon$ 모델 $\left(F_{1}=0\right)$ 을 활성화하여 전체유동장에서 사용할 수 있다.

$$
\begin{aligned}
& F_{1}=\tanh \left\{\left\{\min \left[\max \left(\frac{\sqrt{k}}{\beta^{*} \omega y}, \frac{500 \nu}{y^{2} \omega}\right), \frac{4 \alpha_{\omega^{2} k}}{C D_{k \omega}^{*} y^{2}}\right]\right\}\right. \\
& \phi=\phi_{1} F_{1}+\phi_{2}\left(1-F_{1}\right)
\end{aligned}
$$

여기서 $\phi_{1}$ 와 $\phi_{2}$ 는 각각 $k-\omega$ 방정식과 $k-\epsilon$ 방정식의 계수이다. 선체표면 경계층에는 벽 함수를 사용하였으며 $y^{+}$의 크기를 30 100으로 유지하였다.

\section{5 항주 자세}

항주 시에 흘수에 큰 변화가 없는 배수량형선과는 달리 고속 활주선은 선형의 특성 상 속도가 증가함에 따라 수직 방향의 양 력이 발생하여 Fig. 4에 보이는 바와 같이 트림(Trim)과 부상량 (Sinkage)이 발생하여 속도에 따라 항주 자세가 크게 변화한다.

OpenFOAM에서는 '6DOFSolver' 해석기를 이용하여 트림 및 부상량 등 선체 항주자세를 추정하는데 기본방정식은 식 (11)과 식 (12)의 강체운동방정식(뉴턴 제2법칙)이다.

$$
\begin{aligned}
& \sum F=m a \\
& \sum M=I \alpha
\end{aligned}
$$

여기서 $a$ 는 선형가속도이고 $\alpha$ 는 각가속도이다. 매 시간 식 (13) 과 식 (14)에 의하여 계산된 가속도 $a$ 와 각가속도 $\alpha$ 를 이용 Newmark 방법(Newmark, 1959)을 사용하여 시간 적분하여 새로 운 속도 $v_{n e w}$ 와 각속도 $\omega_{n e w}$ 를 계산하며 속도결과를 격자노드 에 적용하여 격자변형을 실현하며, 선체의 트림과 부상량을 추 정한다.

$$
\begin{aligned}
& v_{\text {new }}=\int_{t_{\text {dd }}}^{t} a d t=v_{\text {old }}+a \Delta t \\
& \omega_{\text {new }}=\int_{t_{\text {odd }}}^{t} \alpha d t=\omega_{\text {old }}+\alpha \Delta t
\end{aligned}
$$

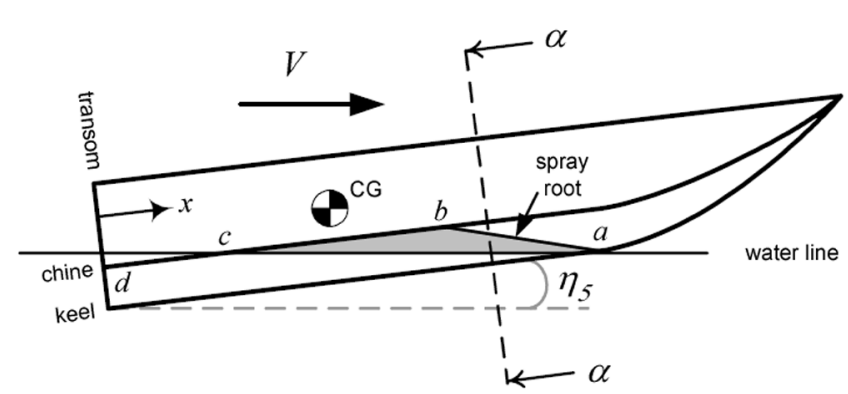

Fig. 4 Planing attitude of planing hull 


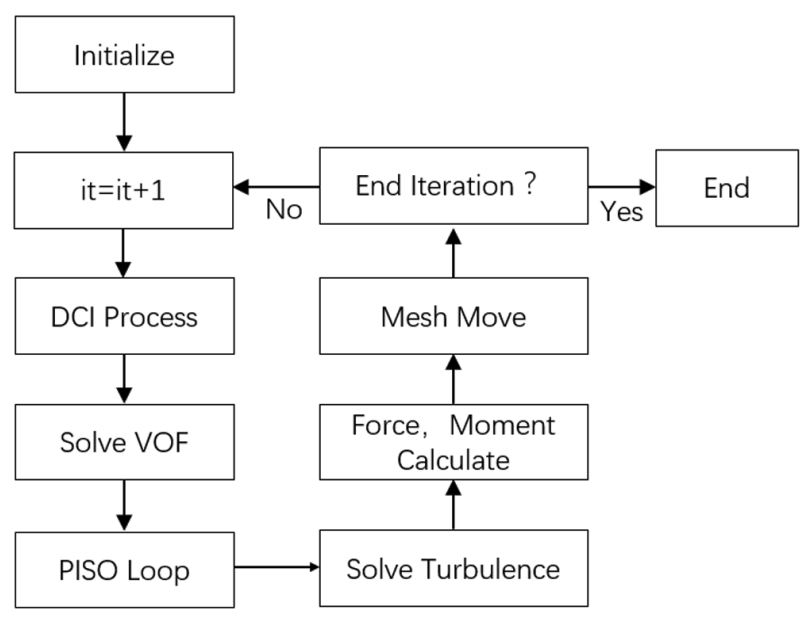

Fig. 56 DOF solver process for overset mesh method

OpenFOAM에서 중첩격자방법을 이용한 유동장 및 항주자세 (선체운동) 해석 과정을 Fig. 5에 간단히 도시하였다.

\section{3. 수치해석 결과}

\subsection{Fridsma 활주선 및 전처리}

본 연구에 사용된 활주선은 Fridsma(1969)에 의해 체계적인 모형시험이 수행된 주형체 활주선으로 Fig. 6 에 $L / B$ 가 4 인 선형 의 선도(Lines)를 보여주고 있다. 주요목은 Table 1과 같다.

전체 수치해석 영역은 길이 방향으로 $8 \mathrm{~L}$ 로, 입구에서 선수까 지 $1 \mathrm{~L}$, 선미부터 출구까지 $6 \mathrm{~L}$ 로 구성되어 있다. 유동장의 폭은 $2 \mathrm{~L}$ 로 지정하였다. 높이 방향으로는 자유수면 하부와 상부에 각 각 $\mathrm{L}$ 을 배치하였다. 운동격자 영역의 크기는 $x$ 축 방향으로 $1.5 \mathrm{~L}, y$ 축 방향으로 $0.4 \mathrm{~L}$ 및 $z$ 축 방향으로 $0.7 \mathrm{~L}$ 로 하였다(Fig. 7). 격자계는 SnappyHexMesh 툴을 사용하여 중첩격자 영역의 경 계면 근처에는 배경격자 영역의 격자 크기와 운동격자 영역의 격자 크기를 동일하게 생성하여 유동장 정보 교환 시 발생할 수 있는 오차를 최소화하였다. 그리고 유속과 압력의 변화가 클
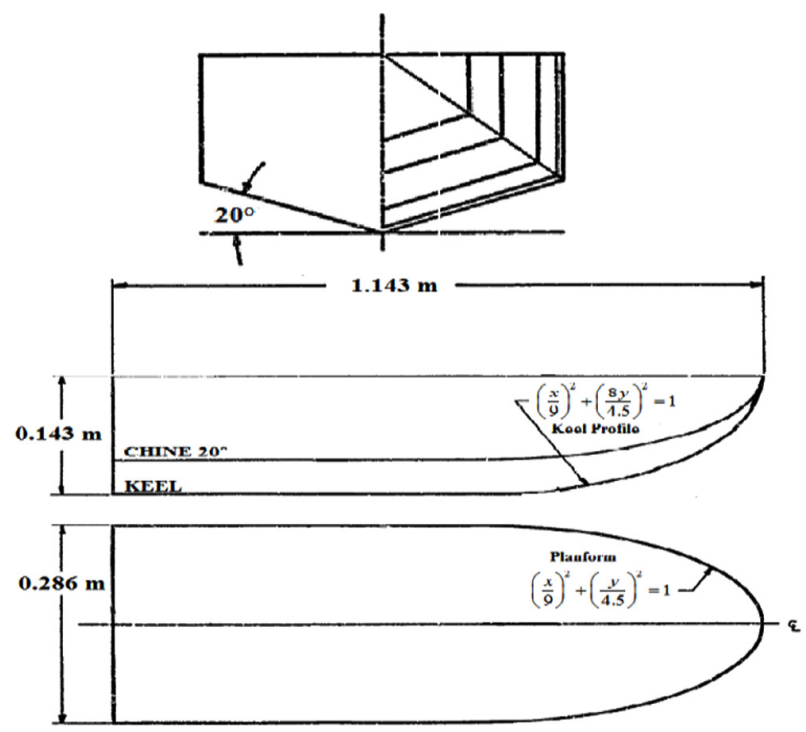

Fig. 6 Lines of Fridsma model $(L / B=4)$
Table 1 Principal particulars of Fridsma model $(L / B=4)$

\begin{tabular}{cc}
\hline \hline Items & Value \\
\hline$L[\mathrm{~m}]$ & 1.143 \\
$B[\mathrm{~m}]$ & 0.286 \\
$T[\mathrm{~m}]$ & 0.069 \\
$L C G$ from $A P[\mathrm{~m}]$ & 0.457 \\
$V C G$ from keel $[\mathrm{m}]$ & 0.084 \\
Deadrise angle & $20^{\circ}$ \\
$\triangle[\mathrm{kg}]$ & 14.219 \\
$I_{z z}=I_{y y}\left[\mathrm{kgm}^{2}\right]$ & 0.5805 \\
\hline
\end{tabular}

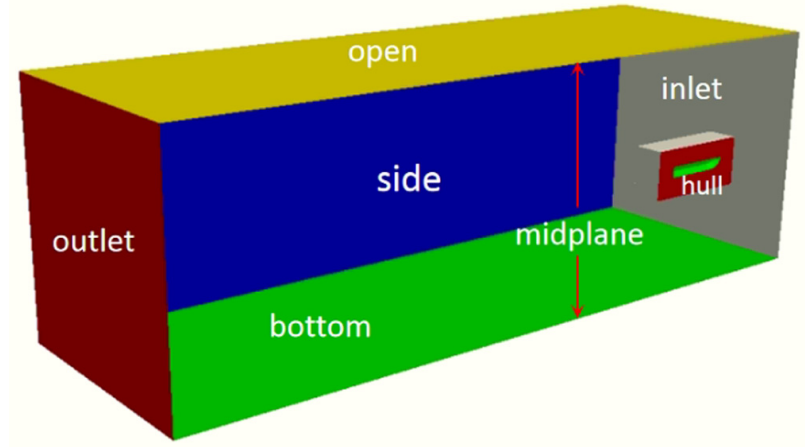

Fig. 7 Flow domain for Fridsma hull

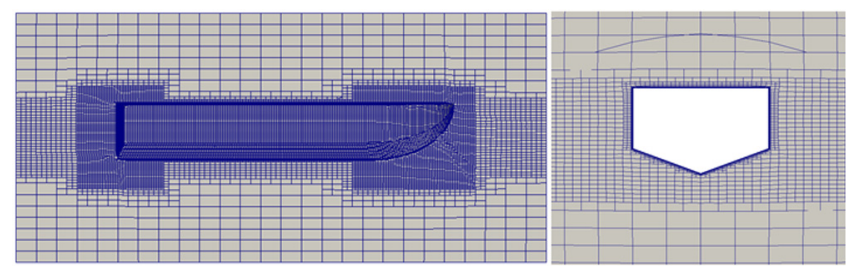

Fig. 8 Meshing for Fridsma hull using SnappyHexMesh

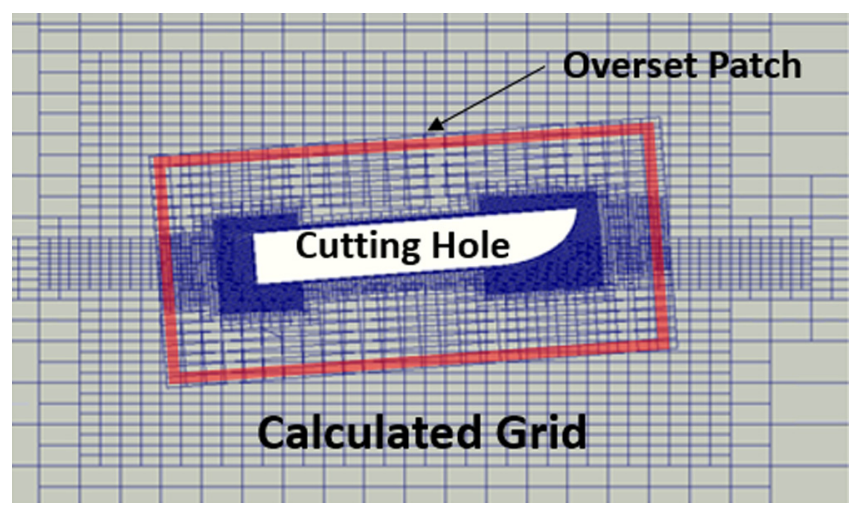

Fig. 9 Multi-mesh pre-processing using overset

것으로 예상되는 선수와 선미 부분에는 Fig. 8 과 같이 국부 세 분할(Local refinement) 기능을 이용하여 정밀한 격자를 생성하 였다. Fig. 9는 중첩격자의 구성을 보여주고 있다.

수치해석에 사용된 각 변수들에 대한 경계조건은 Table 2와 같다. 여기서 'phaseMeanVelocity'는 유동장 출구에서 유량보존 으로 평균속도를 제어하는 조건이고 'variableHeightFlowRate'는 
Table 2 Boundary conditions

\begin{tabular}{|c|c|}
\hline Boundary & Type \\
\hline \multicolumn{2}{|c|}{$<\mathrm{U}$ file $>$} \\
\hline Inlet & fixedValue \\
\hline Outlet & phaseMeanVelocity \\
\hline \multicolumn{2}{|l|}{ Midplane } \\
\hline Side & symmetry \\
\hline \multicolumn{2}{|l|}{ Bottom } \\
\hline Open & pressureInletOutletVelocity \\
\hline Hull & wall \\
\hline \multicolumn{2}{|c|}{$<$ p_rgh file $>$} \\
\hline Inlet & fixedFluxPressure \\
\hline Outlet & zeroGradient \\
\hline Open & totalPressure \\
\hline Hull & fixedFluxPressure \\
\hline OversetPatch & overset \\
\hline \multicolumn{2}{|c|}{$<$ alpha.water file $>$} \\
\hline Inlet & fixedValue \\
\hline Outlet & variableHeightFlowRate \\
\hline Open & inletOutlet \\
\hline Hull & zeroGradient \\
\hline \multicolumn{2}{|c|}{$<$ pointDisplacement file $>$} \\
\hline \multicolumn{2}{|l|}{ Inlet } \\
\hline Outlet & fixedValue \\
\hline \multicolumn{2}{|l|}{ Open } \\
\hline Hull & calculated \\
\hline \multicolumn{2}{|c|}{$<$ zoneID file $>$} \\
\hline \multicolumn{2}{|l|}{ Inlet } \\
\hline \multicolumn{2}{|l|}{ Outlet } \\
\hline \multicolumn{2}{|l|}{ Open } \\
\hline \multicolumn{2}{|l|}{ Hull } \\
\hline \multicolumn{2}{|c|}{$<\mathrm{k}$ file $>$} \\
\hline Hull & kqRWallFunction \\
\hline \multicolumn{2}{|c|}{$<$ omega file $>$} \\
\hline Hull & omegaWallFunction \\
\hline
\end{tabular}

상한(Upper bound)과 하한 (Lower bound)을 통하여 VOF값을 보 정하는 조건이다. 일반적으로 상한은 ' 1 '로 하한은 ' 0 '으로 지정 된다(OpenCFD Ltd., 2017).

수치해석에 사용된 난류모델은 $S S T k-\omega$ 이며 시간이산에 대 하여는 1차 정확도의 Implicit Euler법, 공간이산의 확산항에 대 하여는 중앙 차분 기법으로 처리하며, 대류항에 대하여는 압력 이산, 속도이산, 및 난류이산 등은 2차 정확도인 Linear Upwind 법을 사용하고 $\mathrm{VOF}$ 이산은 안정된 자유수면 유동 결과를 얻을 수 있는 Van Leer법을 사용하였다(Chevrier and Galley 1993).

\section{2 불확실성 해석(Uncertainty analysis)}

$\mathrm{CFD}$ 를 이용한 RANS 방정식에 대한 수치해석 과정에는 입력 변수 오차, 반복 오차, 공간이산 오차, 시간이산 오차 등 다양한
오차가 발생하여 해의 불확실성이 존재한다. 본 연구에서는 Wilson et al.,(2001)과 Stern et al.,(2001)에 제시된 방법을 이용하 여 시간이산 오차와 공간이산 오차의 영향에 대한 불확실성 해 석을 수행하였다.

첫째로, 시간이산 오차 즉, 계산시간 간격에 의한 불확실성 해석을 위하여 식 (15)와 같이 정의된 CFL 수(Courant number) 를 'Small(1)', 'Medium(2)'및 'Large(4)'등 크기 변화의 비율을 2 로 하여 변화시키면서 수치해석을 수행하였다. 각각의 해석에 는 총 격자수 93 만개의 동일한 격자계가 시용되었다. 선속은 활 주 속도인 $F n=1.19$ 를 사용하였다.

$$
C F L=u \frac{\Delta t}{\triangle x}
$$

여기서 $u$ 은 최대 유속이며, $\Delta x$ 와 $\Delta t$ 는 각각 최소격자 간격과 계산시간 간격이다.

Table 3에는 CFL 수 변화에 따른 계산 시간 간격과 수치해석 결과인 총 저항값을 보여주고 있다. $\mathrm{CFL}$ 수가 작아질수록 계산 시간 간격이 작아지고 총 저항값은 Frisma실험 결과에 접근하는 결과를 얻음을 알 수 있다. 결론적으로 수치해석의 시간이산 오 차를 최소화하기 위해서는 CFL 수가 ' 1 '보다 작게 되도록 계산 시간 간격을 설정할 필요가 있다.

둘째로, 공간이산 오차 즉, 격자 크기에 의한 불확실성 해석 의 수행을 위하여 Table 4처럼 배경격자 영역과 운동격자 영역 을 포함한 전체 영역에 'Coarse Mesh'(총 격자수 45만개), 'Medium Mesh'(총 격자수 93만개) 및 'Fine Mesh'(총 격자수 256만개) 등 격자 분할비(Refinement ratio)를 $\sqrt{2}$ 로 하여 3 가지 정렬격자계를 생성하고 수치해석을 수행하여 총 저항, 트림 및 부상량을 추정하였다.

수치해석은 활주 속도인 $F n=1.19$ 에서 수행하였고 시간간격 제어기능(Time step control)을 이용하여 최대 $C F L$ 수를 1이하로 유지하였다.

'Coarse Mesh', 'Medium Mesh' 및 'Fine Mesh' 를 사용하여 구 한 수치해석 결과를 각각 $S_{\text {coarse }}, S_{\text {medium }}$ 및 $S_{\text {fine }}$ 으로 표기하 고 결과를 Table 5 에 정리하였다.

Table 3 Comparison of total resistance varying CFL number

\begin{tabular}{ccccc}
\hline \hline & $C F L$ & $\Delta t$ & Resistance [N] & Diff. \\
\hline Large & 4 & 0.001 & 24.4 & $14.6 \%$ \\
Medium & 2 & 0.0005 & 23.5 & $10.4 \%$ \\
Small & 1 & 0.00025 & 22.9 & $7.6 \%$ \\
\hline \multicolumn{5}{c}{ Exp. } \\
\hline
\end{tabular}

Table 4 Mesh configuration for mesh size test

\begin{tabular}{cccccccc}
\hline & \multicolumn{3}{c}{ Background cells } & \multicolumn{3}{c}{ Motion domain cells } & \multirow{2}{*}{ Total } \\
& $x$ & $y$ & $z$ & $x$ & $y$ & $z$ & mesh \\
\hline Coarse & 42 & 14 & 14 & 26 & 7 & 11 & $0.45 \mathrm{M}$ \\
Medium & 60 & 20 & 20 & 36 & 10 & 16 & $0.93 \mathrm{M}$ \\
Fine & 85 & 28 & 28 & 50 & 14 & 22 & $2.56 \mathrm{M}$ \\
\hline
\end{tabular}


Table 5 Comparison of the results varying mesh size

\begin{tabular}{|c|c|c|c|c|}
\hline & Coarse & Medium & Fine & Exp. \\
\hline Resistance $[\mathrm{N}]$ & 21.76 & 22.9 & 23.49 & 21.28 \\
\hline Difference & & $5.24 \%$ & $2.58 \%$ & \\
\hline$\varepsilon_{32}$ & & & & \\
\hline$\varepsilon_{21}$ & \multicolumn{4}{|c|}{-0.59} \\
\hline$R$ & \multicolumn{3}{|c|}{0.517} & \\
\hline Trim [deg] & 5.305 & 5.65 & 5.71 & 6.9 \\
\hline Difference & & $6.5 \%$ & $1.06 \%$ & \\
\hline$\varepsilon_{32}$ & \multicolumn{3}{|c|}{-0.345} & \\
\hline$\varepsilon_{21}$ & \multicolumn{3}{|c|}{-0.06} & \\
\hline$R$ & \multicolumn{3}{|c|}{0.174} & \\
\hline Sinkage $[\mathrm{m}]$ & 0.03 & 0.0263 & 0.025 & 0.0342 \\
\hline Difference & & $12.33 \%$ & $4.94 \%$ & \\
\hline$\varepsilon_{32}$ & \multicolumn{3}{|c|}{0.0037} & \\
\hline$\varepsilon_{21}$ & \multicolumn{3}{|c|}{0.0013} & \\
\hline$R$ & \multicolumn{3}{|c|}{0.351} & \\
\hline
\end{tabular}

각각의 격자계에 대한 결과로부터 식 (16)-(18)을 이용하여 $\varepsilon_{21}$ 와 $\varepsilon_{32}$ 및 수렴비(Convergence ratio), $R$ 을 구할 수 있다.

$$
\begin{aligned}
& \varepsilon_{21}=S_{\text {medium }}-S_{\text {fine }} \\
& \varepsilon_{32}=S_{\text {coarse }}-S_{\text {medium }} \\
& R=\frac{\varepsilon_{21}}{\varepsilon_{32}}
\end{aligned}
$$

수렴비의 크기에 따라 아래와 같은 수렴 특성을 가진다.

(1) 단순 수렴(Montonic convergence) : $0<R<1$

(2) 진동 수렴(Oscillatory convergence) : $R<0$

(3) 발산(Divergence) : $R>1$

Table 5에 의하면 격자의 크기가 작아질수록 총 저항, 트림 및 부상량의 수렴비 $R$ 의 값이 각각 0.517. 0.174 및 0.351로 최 종 수렴치를 향해 단순 수렴(Monotonic convergence)하는 것을 알 수 있으며 불확실성 해석에 Richardson 외삽법을 사용할 수 있다.

'Coarse Mesh'와 'Medium Mesh'의 총 저항값은 차이가 $5.24 \%$, 트림의 차이는 $6.5 \%$, 부상량의 차이는 $12.33 \%$ 로 비교적 큰 차 이가 추정되었다. 그러나 'Medium Mesh'와 'Fine Mesh'의 경우 에 부상량 차이가 $4.94 \%$ 로 다소 큰 편이나 총 저항과 트림의 차이는 각각 $2.58 \%$ 와 $1.06 \%$ 로 큰 차이 없이 수렴치에 접근하는 경향을 보이고 있음을 알 수 있다. 따라서 본 분석 결과와 수치 해석 수행의 용이성을 고려하여 다음 절에서 수행할 Fridsma 활 주선에 대한 저항 및 활주성능 해석에는 'Medium Mesh'를 기본 격자계로 선정하였다.
수치해석 결과와 Fridsma 실험 결과의 비교는 격자 크기가 작 아질수록 트림은 실험치에 접근하는 경향을 보이고 있으나 총 저항값과 부상량은 공히 실험치와의 차이가 커짐을 알 수 있다. 즉, 저항과 부상량의 상호 상관관계가 트림보다는 매우 큼을 알 수 있다. 수치해석 결과가 실험 결과에 수렴하지 않는 경향은 활주선 저항 및 활주성능 관련 타 CFD해석 연구 결과 $(\mathrm{Fu}$ et al., 2012; Marcello, 2015; Mousavirrad et al., 2015) 등에도 공통적으 로 나타나는 결과로 이러한 현상을 규명하기 위해서는 수치해 석 과정에 존재하는 다른 오차 요소들에 대한 추가적인 분석은 물론 활주선 모형시험 과정에서 발생할 수 있는 실험 오차 요 소들 특히, 무게분포, 예인 방법 및 예인점에 대한 검증이 필요 할 것으로 본다.

Wilson et al.(2001)과 Stern et al.(2001)의 절차에 따라 Richardson 외삽법을 이용하여 격자크기의 변화에 따른 불확실 성 해석을 수행하였다. 식 (19)-(23)에 걸쳐서 수렴차수, $P_{G}$, 보 정계수, $C_{G}$, 불확실성, $U_{G}$, 수정된 오차 $\delta_{G}^{*}$, 및 수정된 해, $S_{c}$ 를 각각 구할 수 있다. 여기서 한계 수렴차수, $P_{G_{\text {est }}}$ 의 값은 2 를 사 용하였으며 격자 분할비, $r$ 은 $\sqrt{2}$ 를 사용하였다.

$$
\begin{aligned}
& P_{G}=\frac{\ln \left(\varepsilon_{32} / \varepsilon_{21}\right)}{\ln (r)} \\
& C_{G}=\frac{r^{P_{G}}-1}{r^{P_{G+t}}-1} \\
& U_{G}=\left|C_{G}\left(\frac{\varepsilon_{21}}{r^{P_{G}}-1}\right)\right|+\left|\left(1-C_{G}\right)\left(\frac{\varepsilon_{21}}{r^{P_{G}}-1}\right)\right| \\
& \delta_{G}^{*}=C_{G}\left(\frac{\varepsilon_{21}}{r^{P_{G}}-1}\right)
\end{aligned}
$$

$S_{c}=S_{\text {fine }}-\delta_{G}^{*}$

공간이산 오차 즉 격자크기의 변화에 따른 불확실성 해석 결 과를 Table 6에 정리하였다.

'Fine mesh'에 대한 총 저항의 불확실성은 $2.7 \%$, 트림과 부상 량의 불확실성은 각각 $1.9 \%$ 와 $8 \%$ 로 추정되었다. 그리고 격자의 크기가 0 으로 수렴될 경우에 총 저항, 트림 및 부상량은 각각 $24.08 \mathrm{~N}, 5.77^{\circ}$ 및 $0.0249 \mathrm{~m}$ 로 수렴할 것으로 추정된다.

Table 6 Results of uncertainty analysis varying mesh size

\begin{tabular}{ccccccc}
\hline \hline Study & $R_{G}$ & $P_{G}$ & $C_{G}$ & $U_{G}$ & $\delta_{G}^{*}$ & $S_{c}$ \\
\hline Resistance & 0.517 & 1.9 & 0.932 & 0.633 & -0.59 & 24.08 \\
$\% S_{\text {fine }}$ & & & & $2.7 \%$ & $2.5 \%$ & \\
Trim & 0.174 & 5.05 & 4.75 & 0.107 & -0.06 & 5.77 \\
$\% S_{\text {fine }}$ & & & & $1.9 \%$ & $-1 \%$ & \\
Sinkage & 0.351 & 3.02 & 1.85 & 0.002 & 0.0013 & 0.0249 \\
$\% S_{\text {fine }}$ & & & & $8 \%$ & $5.2 \%$ & \\
\hline
\end{tabular}




\section{3 활주성능 해석}

수치해석 대상 활주선인 Fridsma 선형의 주요목은 Table 1와 같고, 선속은 프루드 수가 $0.59,0.89,1.19,1.48$ 및 1.78 의 5 가지 선속을 선택하여 배수량형 저속상태부터 활주선형 고속상태를 포함하도록 하였다.

격자구성은 불확실성 해석에서 분석한 결과를 바탕으로 총 격자는 93만개의 'Medium mesh'를 사용하였으며 최대 CFL 수 는 1 로 지정하였다.

Fig. 10은 최대 CFL수가 1로 유지될 때 속도에 따른 계산 시 간 간격(Delta $t$ )을 보여주고 있다. 속도가 빨라질수록 계산 시간 간격이 0.0006초부터 0.0002초까지 점점 작아짐을 알 수 있다. 또한, 계산 시간 간격의 빠른 수렴은 유동장 전체의 속도와 압 력값들이 빠르게 수렴함을 의미한다.

Fig. 11은 프루드 수 1.19일 때 자유수면의 파고 분포를 보여 주고 있다. 전반적으로 명확한 캘빈 파형을 볼 수 있으며 선미 부 후류에 발생하는 루스터(Rooster) 현상을 확인할 수 있다.

Fig. 12는 저속부터 고속까지 선속의 변화에 따른 선저면의 압력 분포를 보여주고 있다. 선속이 증가하면서 부상과 트림이 발생함에 따라서 전반적으로 침수면적이 감소하는 경향을 볼 수 있다. 그러나, 프루드 수가 1.19에서 1.48로 증가할 때는 침 수면적이 증가함을 볼 수 있는데 그 이유는 프루드 수가 1.19보 다 커지면 부상량의 증가율은 둔화되고 트림은 지속적으로 감 소하면서 생기는 현상으로 추정할 수 있다. 침수면적의 변화는 총 저항치에 직접적인 영향을 주는 요소이다.

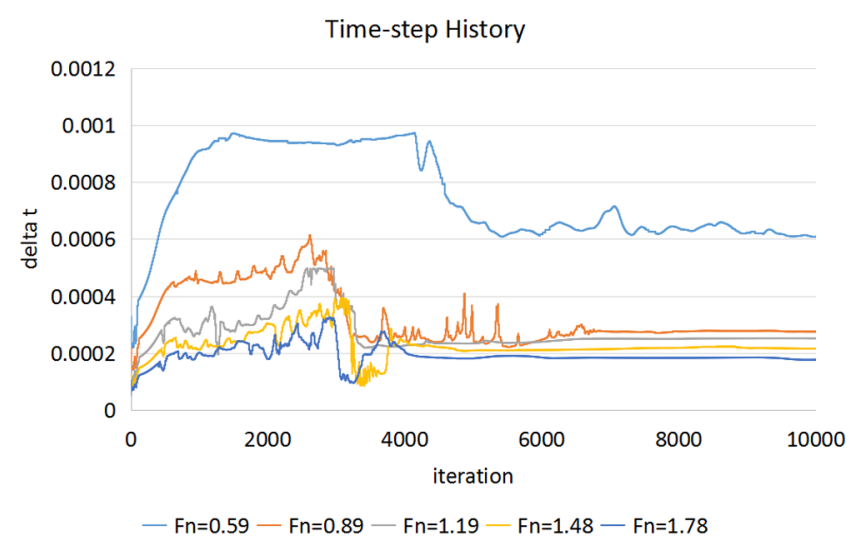

Fig. 10 Time step history limited by $\operatorname{Max} C o=1$

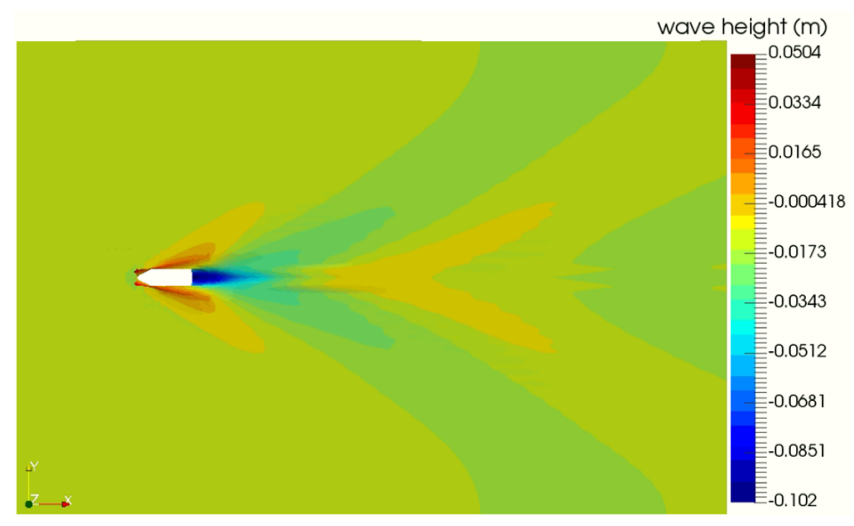

Fig. 11 Free surface wave contour $(F n=1.19)$

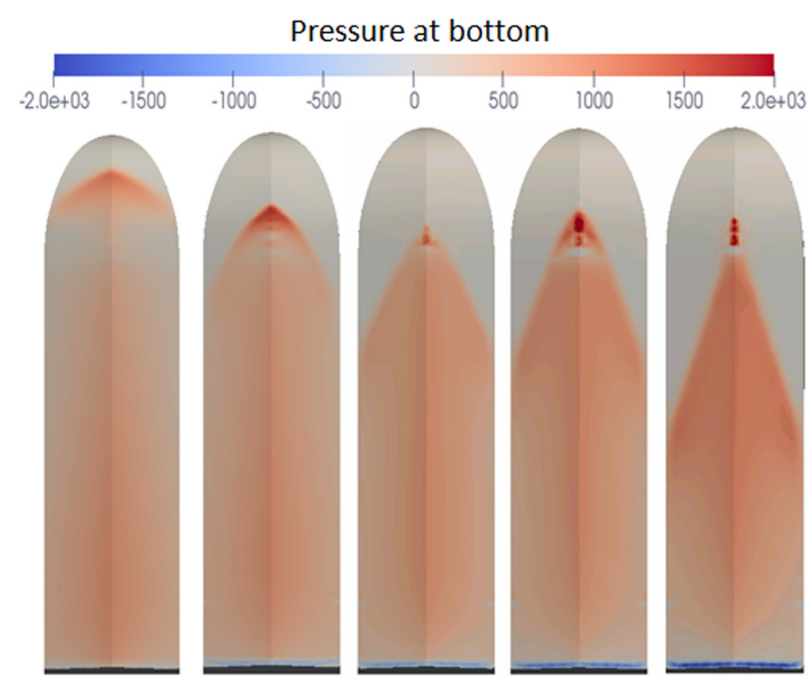

Fig. 12 Pressures on hull bottom at $F n$ 0.59, 0.89, 1.19, 1.48, 1.78 (from left to right)

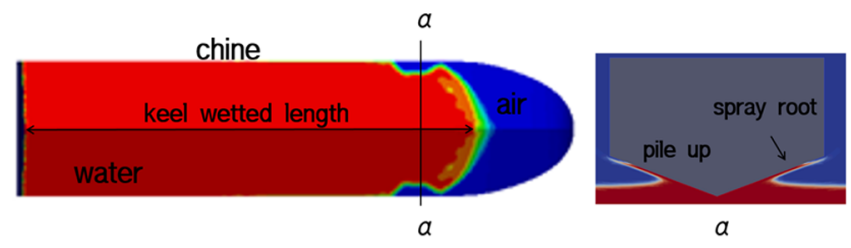

Fig. 13 Wetted surface profile on bottom and spray characteristics at $\alpha-\alpha$ surface $(F n=1.19)$

Fig. 13은 프루드 수가 1.19 인 경우에 VOF의 변화를 통하여 선저 접수면의 형상을 보여주고 있다. 붉은색 부분은 $\mathrm{VOF}$ 가 1 인 부분으 로 격자가 물로만 채워져 있는 부분이고 푸른색 부분은 VOF가 0 으로 격자 내에 공기만 있는 부분이다. 또한, 선저면 기선 부분부 터 Chine-dry 영역과 Chine-wet 영역을 볼 수 있으며 Chine-dry 영역 인 $\alpha-\alpha$ 단면에 발생하는 스프레이 현상을 확인할 수 있다.

Fig. 14-16은 각각 속도의 변화에 따른 총 저항, 부상량 및 트 림의 변화를 보여주고 있다. 삼각형(OpenFOAM)은 본 연구의 결과이며 실험 결과, Mousaviraad et al.(2015)의 결과 및 Savitsky 경험식과의 비교를 통하여 수치해석 결과를 검증하였다.

총 저항의 경우에 부력의 영향이 지배적인 저속에서는 4 가지 방법에 큰 차이 없으나 속도가 증가하고 수동역학적인 힘인 양

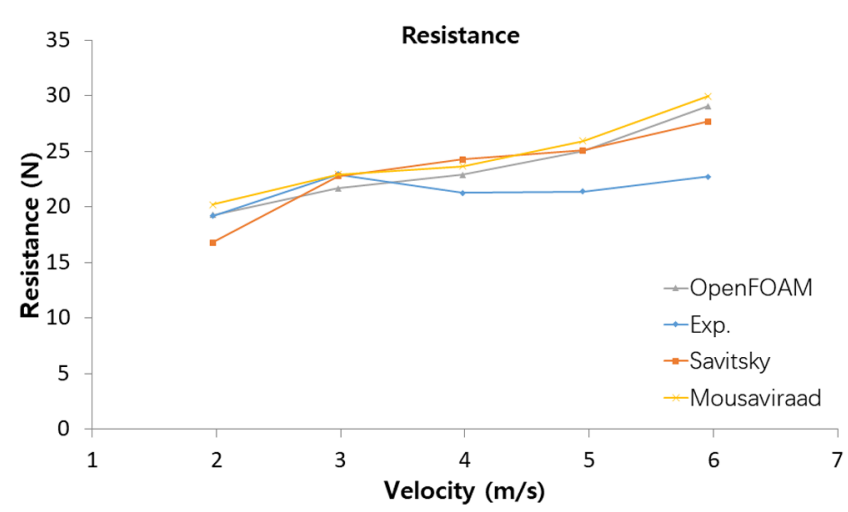

Fig. 14 Comparison of resistance 


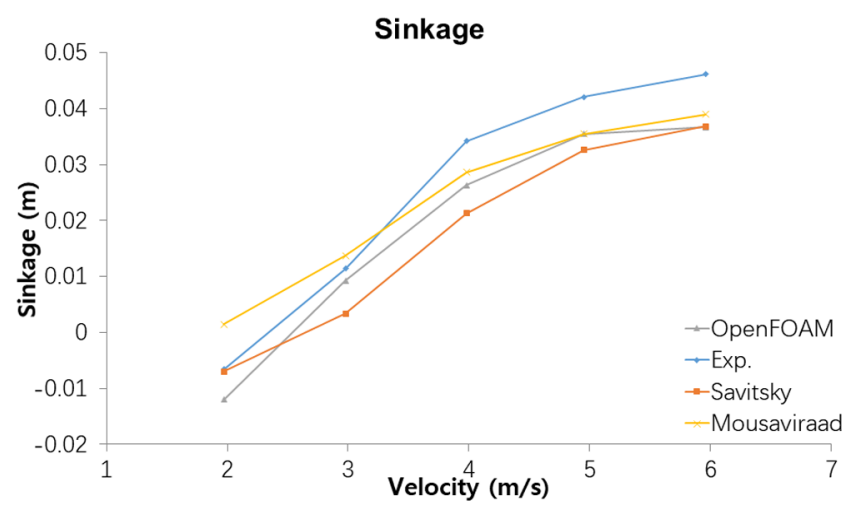

Fig. 15 Comparison of sinkage

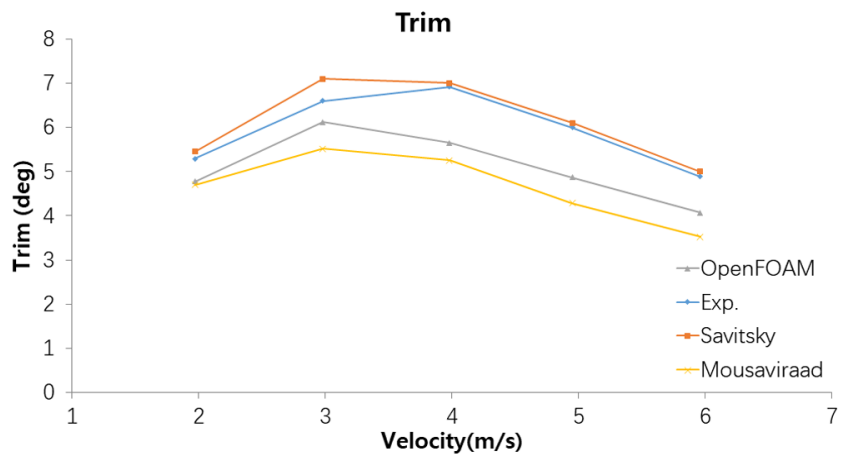

Fig. 16 Comparison of trim

력의 영향이 증가하면서 본 연구 결과와 Mousaviraad의 결과 및 Savitsky 경험식 결과는 비교적 잘 일치하면서 증가하지만 실험 값은 전반적인 변화의 경향은 일치하나 크기가 작고 속도가 증 가함에 따라 차이가 커짐을 알 수 있다.

부상량의 경우에도 정성적인 변화의 경향은 일치하나 저속을 제외한 대부분의 속도 구간에 걸쳐서 실험값이 가장 크고 Savitsky 경험식은 가장 작은 값을 가지고 있음을 알 수 있다. 본 연구의 결과와 Mousaviraad의 결과가 중간값을 가지고 있으 나 본 연구의 결과가 실험값의 변화 경향을 대체로 따라가고 있음을 알 수 있다. 실험 결과와 CFD 결과가 총 저항과 부상량 의 크기에서 역전되는 경향을 보여주고 있는 것으로 볼 때 총 저항에 미치는 부상량의 영향이 매우 큼을 알 수 있다.

트림의 경우는 실험값과 Savitsky 경험식 결과가 전반적으로 잘 일치하고 있으며 본 연구의 결과는 실험값과 큰 차이를 보 여주고 있으나 Mousaviraad의 결과보다는 실험값에 근접한 결 과를 보여주고 있다.

앞 절 '불확실성 해석'에서도 기술한 바와 같이 활주형선에 대한 본 연구의 결과를 포함한 대부분의 CFD 결과가 Fridsma의 실험 결과와 크게 차이가 남을 볼 수 있는데 그 원인을 규명하 기 위하여는 CFD 수치해석에서 발생할 수 있는 다양한 오차 요 소들은 물론 모형실험의 준비 및 수행과정에서 발생하는 불확 실성에 대한 보다 근본적인 연구가 필요할 것으로 본다.

\section{4. 결 론}

첫째, 본 연구를 통해서 OpenFOAM 프로그램을 이용하여 주
형체 고속 활주선에 대한 저항성능 및 항주자세를 수치해석하 는 방법을 정립하였다.

둘째, 주형체 활주선의 저항 및 항주자세 수치해석에 대하여 계산시간 간격과 격자크기의 변화에 대한 불확실성 해석을 수 행한 결과 각각의 물리량에 대한 불확실성의 크기와 Richardson 외삽법을 사용하여 격자의 크기가 0 으로 수렴될 경우에 수렴값 (참값)을 추정하였다.

셋째, 활주선 고속항주 시 자유수면의 파고 분포와 Chine-dry 영역에서의 스프레이 현상을 수치해석으로 확인하였고 선속 변 화에 따른 선저 접수면의 형상 변화를 통하여 저속상태부터 고 속상태까지의 활주현상을 확인할 수 있었다.

넷째, Fridsma의 주형체 활주선에 대하여 고속 항주시 저항성 능과 항주자세를 추정하였다. 총 저항 값과 부상량의 경우에 타 $\mathrm{CFD}$ 결과 및 경험식 결과와 대체로 일치하는 경향을 보여주고 있지만 고속 활주 영역으로 갈수록 실험값과의 차이가 커지는 결과를 얻었다. 트림 결과는 전 속도 영역에서 변화의 경향은 대체로 일치하나 실험값과 비교적 큰 차이를 보여주고 있다.

다섯째, 활주형선에 대한 본 연구의 결과를 포함한 대부분의 $\mathrm{CFD}$ 결과가 Fridsma의 실험 결과와 정성적인 변화의 경향은 일 치하나 크게 차이가 남을 볼 수 있는데 그 원인을 규명하기 위 해 $\mathrm{CFD}$ 수치해석과 모형실험에 존재하는 다양한 불확실성에 대한 연구가 필요할 것으로 본다.

본 연구 결과를 바탕으로 향후에는 비주형체 활주선에 대한 정수 중 저항성능 및 항주자세 추정 연구, 활주선의 파랑 중 운 동성능 추정에 대한 연구 및 $\mathrm{CFD}$ 수치해석과 모형실험의 불확 실성에 대한 연구를 수행할 예정이다.

\section{References}

Bustos, D.S.H., Alvarado, R.J.P., 2017. Numerical Hull Resistance Calculation of a Catamarán Using OpenFOAM. Ship Science and Technology, 11(21), 29-39. https://doi.org/10.25043/ 19098642.150

Chevrier, P., Galley, H., 1993. A Van Leer Finite Volume Scheme for The Euler Equations on Unstructured Mesh. Mathematical Modelling and Numerical Analysis, 27(2), 183-201.

Cucinotta, F., Sfravara, F., 2018. Experimental and Numerical Hydrodynamic Analysis of a Planing Hull Pleasure Boat. International Journal of Applied Engineering Research, 13(1), 30-39.

Fridsma, G., 1969. A Systematic Study of the Rough-water Performance of Planing Boats. Davidson Laboratory Report, 1275.

Fu, T.C., O'Shea, T.T., Judge, C.Q., Dommermuth, D., Brucker, K., Wyatt, D.C., 2012. A Detailed Assessment of Numerical Flow Analysis (NFA) to Predict the Hydrodynamics of a Deep-V Planing Hull. 29th Symposium on Naval Hydrodynamics, Gothenburg, Sweden, 26-31.

Go, G.S., Lee, E.T., Ahn, H.T., Kim, S.I., Chun, S.Y., Kim, J.S., Lee, B.H., 2016. 6DOF Simulation and Determination of Hydrodynamic Derivatives of Underwater Tow-Fish Using 
CFD. Journal of the Society of Naval Architects of Korea, 53(4), 315-328. https://doi.org/10.3744/SNAK.2016.53.4.315 Hassan, G., Kamarlouei, M., Veysi, S.T.G., 2015. A Hydrodynamic Methodology and CFD Analysis for Performance Prediction of Stepped Planing Hulls. Polish Maritime Research, 22(2), 23-31. https://doi.org/10.1515/pomr-2015-0014

Islam, H., Soares, C.G., 2017. Prediction of Ship Resistance in Head Waves Using OpenFOAM. Maritime Transportation and Harvesting of Sea Resources, Taylor \& Francis Group.

Marcello, I., 2015 Hydrodynamics of Planing Hull by CFD. Thesis Master's Degree in Naval Engineering of Naples University. Mousaviraad, S.M., Wang, Z.Y., Stern, F., 2015. URANS Studies of Hydrodynammic Performance and Slamming Loads on High-speed Planing Hulls in Calm Water and Waves for Deep and Shallow Conditions. Applied Ocean Reseacch, 51, 222-240. https://doi.org/10.1016/j.apor.2015.04.007
Newmark, N.M., 1959. A Method of Computation for Structural Dynamics. Journal of the Engineering Mechanics Division, 85(3), 67-94.

OpenCFD Ltd., 2017. OpenFOAM User Guide.

Savitsky, D., 1964. Hydrodynamic Design of Planing Hulls. Marine Technology and SNAME News, 1(4), 71-95.

Stern, F., Wilson, R., Coleman, H.W., Paterson, E., 2001. Comprehensive Approach to Verification and Validation of CFD Simulations - Part 1: Methodology and Procedures. Journal of Fluids Engineering, 123(4), 793-802. https://doi.org/10.1115/ 1.1412235

Wilson, R., Stern, F., Coleman, H.W., Paterson, E., 2001. Comprehensive Approach to Verification and Validation of CFD Simulations - Part 2: Application for Rans Simulation of a Cargo/Container Ship. Journal of Fluids Engineering, 123(4), 803-810. https://doi.org/10.1115/1.1412236 